\title{
Research on Vehicles Rock art Image of Yinshan and Helan Mountain and Its Teaching Enlightenment
}

\author{
Aiping Gou and Guangping Gou* \\ Gou Aiping, Associate Professor, Xi'an Academy of Fine Arts, Doctoral Candidate of Minzu \\ University of China ,710065
}

Gou guangping,Art college of Xi'an university,710065

Keywords: Yanshan; Helan Mountain; Vehicles rock art; Cultural attribute; Teaching enlightenment

\begin{abstract}
Helan Mountain in Ningxia province of China and Yinshan in Inner Mongolia remain a large number of ancient rock arts and become an important distribution area of rock arts in China. Vehicle rock art has been closely related to human activities such as war, travel, migration, commerce and hunting. Therefore, the vehicle rock art has become one of the important contents of the study on ancient culture. In the field of rock art, most of researchers paid more attention to the problem of age and communication, while have not yet discussed the cultural attributes of vehicle rock art. On the basis of the study of the age and the transmission of the vehicle, the author analyzed the cultural attributes of the vehicle rock arts of the Helan Mountain and the Yinshan, and specifically, combined with the cultural attributes of the rock arts of the Yinshan and Helan Mountain vehicles in order to explain attributes of the vehicle rock art, hope to interpret the enlightenment of the relationship between rock art and local culture, foreign culture, and the research methods.

There are three kinds of opinions on the origin and spread of the vehicle, one is made in China and the other is from West Asia. The third opinion is that western vehicles are transmitted to China through Central Asia or the Caucasus. There are rock art researchers believed that Hang Aishan and Altai are the route of the vehicle eastbound China. Yinshan and Helan Mountain are close to each other in the area, while emphasis points of the culture are different, although the two vehicles have nuances of rock paintings, the whole body are in the northern cultural areas. Therefore, it would be feasible to place the two sides in the overall cultural space.
\end{abstract}

\section{The Distribution of Vehicles Rock Art in Helan Mountain and Yinshan}

Ninglan Helan Mountain has found 25 vehicles rock arts, 12 in Helan port, 1 in Dashulin gutter, 4 in Siyan wells, 1 in Lugou Lake, 6 in Damai land, 1 in Shima Bay. The majority of Helan Mountain vehicle rock arts are two-wheelers, the number is 17, most of them are double horses driving, a few did not depict the horse, the majority of vehicles had single house, double horse wheel shape is circular plate. Helan Mountain did not find a four-wheeled carriage, a small number of vehicles rock was only carved one side of the wheel, this type of carriage was the hub style, therein the car has two horses in driving. There were a small number of vehicles rock art was only carved out of the wheel, may referring to the symbol of the vehicle.

Most of Yinshan vehicle rock arts are distributed in the eastern part of the Yinshan Daqingshan Piaolan temple area, there are 25 in tempered temple, 2 in Jigongli Hailuo Si, 1 in Han Wulashan, 1 in Daba ditch, 2 in Tuolin ditch, 1 Aguigou, 2 in Wulatezhongqi, totally 34. Among the 34 Yinshan vehicle rock arts, 21 were double-wheeled and double-wheeled vehicles, of which 17 were round plates, 4 were hubs, 3 were not carved, and 4 were road or rutting traces, surrounded by people and animals, indicating that it was related to hunting, grazing or other activities. Most vehicles rock arts in Yinshan were double driving horse, with car Yu, cycling vehicles. Yinshan vehicle rock arts also have a four-wheeled carriage rock arts, one takes the reins and standing in front of the horse. In the Yanshan Dam ditch we also found a special vehicle rock art, it is a box car, completely different from other vehicles rock, and closer to modern Mongolian grassland cattle car. Yinshan and Helan Mountain vehicle rock are composed by the wheels, car, car Yu, axles, car balance and driving 
horse, the vehicles in the two areas are mostly double-wheeled motor carts, the trunks are a single house, Cheyu is square and round, wheel is the circular plate and hub-style, driving horse are cost to trunks by back, limbs are out, the forms of two horse looking at each other are relatively rare.

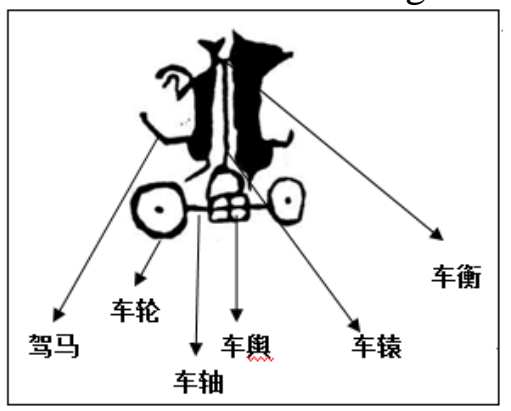

Figure 1. Rock art structure

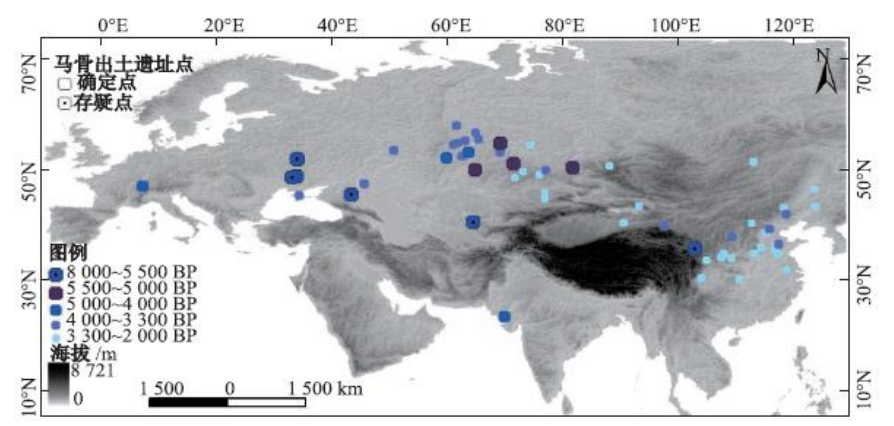

Figure 2. The origin and dissemination of Horse in the Eurasian continent

\section{The Cultural Attributes of Vehicles Tracing and Vehicle Rock Arts}

According to the existing archaeological materials, the first vehicle was originated in Mesopotamia, the age of $3500 \mathrm{BC}$ to $3100 \mathrm{BC}$ or so. The oracle of "Car" word is close to the text of the seal on the shape of the car with the shape of the rock, "in oracle, there are some records on the field hunting and war. In addition to involving field hunting, war, Jinwen materials also have the detailed record of many carriage structure in the ancient Chinese literature on the ancient vehicles, Xuanyuan emperor's name is also related to the repairer, "Han • Ancient and Modern People Table": "Zhang Yan said: due to earth, then be the king, so called the Emperor, for the Xuanwei clothes, so called the Regulus. "' Road History (before the seven) - Xuanyuan ": " Xuanyuan lives in the north of the mulberry, find the wisdom, see the wind that can push the tent, so that he made the car, taking the tree as $\mathrm{Pu}$, bar as the Xuan, straight wood to form the house, to respect the high lord, it is said Xuanyuan. " Xunzi • shelter :" Xi Zhong as the car, Chendu made the vehicles,and the father is good at driving" Xi Zhong was said to be manager who controlling the vehicles in Xia Yu times, Cheng Du was said that he first invent the driving skills, the father was good at driving. "Lu's Spring and Autumn• Jun Shou" mentioned in the construction and other things," this is the car, made by the number of officers. Xi Zhong made the car, Cang Jie made the word "" Xinyu, Daojidiyi": " rivers staggered, weathered blocked, the country never separated, there is no use of the boat, and go deep and far; so Xi Zhongnai take radial round, because straight for the house, driving horse cattle, use floating boat sticks to replace manpower. "

Some researchers believe that China's late-stage carriage came from West Asia, the ancient Chinese books recorded in Xia Dynasty. In May 1996 - April 1997, in Henan Yanshi mall ruins people found the age of the relics and rutting traces is no later than lower section of the early Shang culture in Zhengzhou Erli Gang, Yanshi mall double wheel rutting archaeological relics proved in the early days of the emergence of vehicles, this discovery will make the history of China's car move forward 200-300 years. "No later than the Shang Dynasty, China has been able to be repairer, and from the unearthed relics to see, at that time, the car in the structure of the general shape has a 
certain maturity." Sun Ji thought that the car alone to the car was overly completed in the Western Han Dynasty. Zhang Wenjing thought Inner Mongolia Yinshan vehicle rock paintings of the age limit set in the Shang Dynasty or earlier, and the lower limit set in the Spring and Autumn Period, part of the vehicle rock painting time is likely to follow this. According to Sun's research on the model, Yinshan and Helan Mountain vehicle rock paintings are basically independent car, the age limit was in the early Shang Dynasty or earlier, the lower limit extended to the Western Han Dynasty is a reasonable presumption. Scholars think horse was originated in Kazakhstan about 5500 years ago, from 5000 to 4000 years ago from the birthplace to the spread of the east and west sides, from 4000 to 3600 years came into China Ganqing area. In Gansu Yongjing Qijia cultural cemetery, people found the remains of the horse, in Anyang, Xi'an, Shandong and other commercial sites people found many car horses buried in the pit, indicating that at least 3300 years ago, the horse has occupied an important position in the transport in the Central Plains.

In the late of Shang Dynasty and Zhou Dynasty, in some sites and tombs, chariot and weapons are unearthed in large numbers. The vehicles made during the Shang and Zhou dynasties are very sophisticated, far from the state of the vehicle. Therefore, argument on the existing vehicles of Xia dynasty in the literature should be historical rather than legend. With the increase in vehicle use, the importance of the car and the growing social status. "Interpretation of the release" in the car on the different status of the use of different vehicles in the record, "the emperor said by the jade, jade car also, ... Hu slave car, $\mathrm{Hu}$ sin into the official slaves, The car is also a symbol of identity, and gradually began to pay attention to the gorgeous appearance of the decoration, the car has become the rights, status and rank of the car of owner. Signs, car system is improving, the car's ideological color is growing. There is no doubt that the vehicle as a symbol of the level of identity, and Zhou Dynasty country graveyard strict grave can explain the problem, different levels of burial car and car equipment and the shape of the different carved body weight is a symbol of the owner. The level of wealth and wealth of the car is treated as a symbol of the identity of the aristocratic identity, status were even higher than other rituals. In the Western Zhou Dynasty, carriage and car in the etiquette occupied an important position. Therefore, the carriage should not only emphasize its practicality as a weapon of war, the carriage is also a ritual. In addition to as a means of transport, such as weddings and funerals, in the pilgrimage and ritual activities they also use the car. In summary, the ancient Chinese, vehicles was produced earlier, although they might be affected by foreign culture, but still had a local characteristic. The vehicle was originated from traffic, field hunting, war and other practical purposes, then gradually obtained multiple functions, and became a ritual, then played a role in the field of ideology.

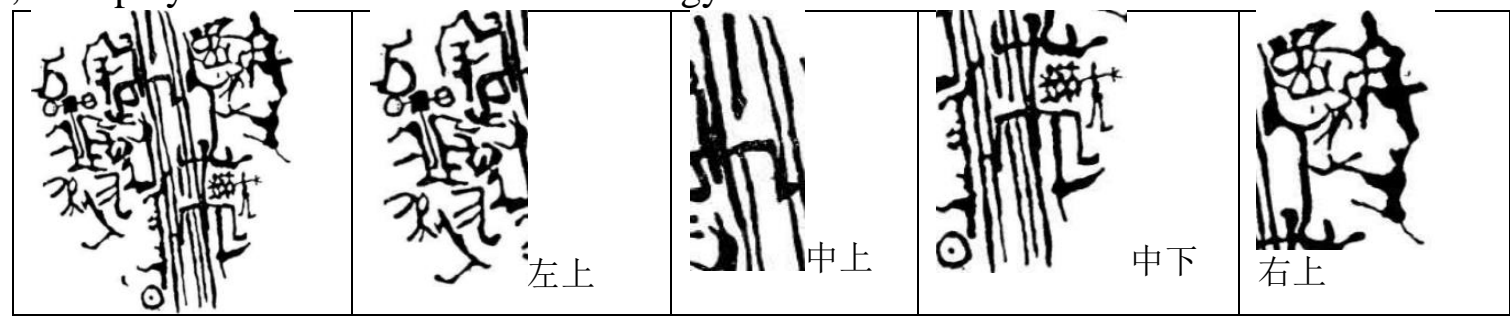

Figure 3. Overall decomposition of vehicle rock art

Fig. 3 is the Inner Mongolia Yinshan Lama Temple temple car rock arts, the rock arts consist of animals, people, roads or rutting, vehicles, there is a stacking relationship between them. The author will divide them into four regions of the whole rock, the top left is composited of animals and vehicles, vehicle rock arts was for the round plate wheels, square Cheyu, single house, set horse, horse back by car, vehicle rock art is around the distribution of a few animal. The top right of the screen is also a number of animals, which indicates that the vehicle is associated with field hunting or grazing. The top of the screen is a road or rut trace, the road shows that the activities of this region is more frequent. In the lower part of the description of the two squat-style humanoid, of which a squatting humanoid stacked on the road below, indicating squatting man-made is later than the rutting road rock paintings, the department of tail ornaments is frog posture. Anati, E. think this is a prayer image. $\mathrm{A} \cdot$ Lommel believes that the pacific ridge squatting is an ancestral worship and 
reproductive worship. Chinese scholars have a variety of cultural explanations for squatting human images. The main view is that it is a reproductive figure or a dancer's image. The age is from Neolithic Age to the Bronze Age, and there are good reasons to think that the squatting of the humanoid is related to the ancestral worship in Shamanism. Therefore, the ancestral worship and witchcraft nature of the squatting figure on the road, indicating that the vehicle, animal and human form are formed between a witchcraft, sacrifice and the promotion of the relationship between wealth and rights, the purpose is praying for auspicious and wealth.

Among the 34 rock arts in the Yinshan area, therein, 10 were rock arts for the single vehicle, 24 were rock arts associated with the contents of animals and animals, characters and symbols, and 5 of the rock arts are associated with the characters that were squatting Humanoid, Yinshan vehicle rock arts have 4 associated roads. There are 8 volcanic rock arts in the Helan Mountain, and 3 are wheel rock arts and 14 are associated images of vehicles and animals or characters, symbols and so on. In Yinshan and Helan Mountain there are a small number of vehicles associated with the hunting map, with the vehicle associated symbols that have concentric circles, hoof and other symbols. Overall, the total number of vehicle rock arts in the Yinshan area was 24, accounting for $70.6 \%$ of the total number of rock arts in the Yinshan vehicle. The total number of rock arts in the Helan Mountain area was 14, accounting for $56 \%$ of the total number of rock arts in Helan Mountain. Rockery and animal, symbol-related content contains are more witchcraft or primitive religious elements, "rock art by the animal, its meaning is not only the meaning of the image itself, often metaphor of a mysterious idea. For example, chisel Or painting an animal, often not simply show the animal, but have the animal image metaphor of hunting witchcraft ... rock arts, indeed made in witchcraft, or it infiltrated the witchcraft and services for witchcraft, ... "Therefore, according to the vehicle rock arts associated with the information and other information we can see, Yinshan and Helan Mountain vehicle rock arts are mostly associated with the worship and witchcraft activities.

According to "The distribution characteristics and content analysis of vehicle rock art and landscape in the eastern part of Eurasian grassland " Author Tsugaru Barry Seoul listed the ABC three regional vehicle rock arts of the shape of the view, compared with Yanshan and Helan Mountain vehicle rock art and the Eurasian grassland the three area, there are similar types of vehicle rock arts, but the Eurasian grassland vehicle rock modeling are more diversified, complex, Yanshan and Helan Mountain vehicle rock modeling are more uniform, simple car, Yinshan and Helan Mountain vehicle rock art in the art are closed to the performance of the way of the Mongolian vehicle rock arts. In addition, in the Yinshan, we only found a four-wheeled carriage rock art, the modeling is different from Eurasian grassland, Helan Mountain does not appear four-wheeled carriage, therefore, two-wheeler is more suitable for terrain environment in Yinshan and mountain areas of Helan Mountain.

In addition, Yinshan and Helan Mountain vehicle rock arts in the cultural properties to reflect the three types content, first, Yinshan and Helan Mountain vehicle rock art is related to field hunting, grazing activities, and accompanied by witchcraft composition; second, vehicle rock art is a cultural symbol, is the symbol of wealth and rights; Third, the vehicle rock art is an integral part of the cultural system, is the symbol to communicate the gods, worship ancestors, access to material and spiritual wealth. In general, according to the time of manufacture of Chinese vehicles, the Maoming route and the close relationship between Yinshan and Helan Mountain and the cultural space of the Central Plains, the models in the rock arts of the Yinshan and Helan Mountain vehicles will be influenced by the culture of the Central Plains. For example, the vehicle rock arts belong to the northern part of the nomadic culture, Yanshan and Helan Mountain vehicle rock arts in the artistic style will also be affected by the northern grassland nomadic culture. Therefore, the Yanshan and Helan Mountain vehicle rock arts are the cultural products of the northern grassland nomadic culture and the Central Plains vehicle culture. 


\section{Research Methods and Teaching Enlightenment of Three Vehicle Rock Art Images}

Yinshan and Helan Mountain vehicle rock art research method is a new attempt, with three aspects of new things, firstly from the point of view on Yinshan and Helan Mountain vehicle cultural properties to carry out the exploration and discussion, through the interpretation of cultural attributes on the relationship between the origin of the vehicle rock art and the surrounding culture, and further discuss the question of the vehicle rock art origin, attributes and time, the kind of research method suggests that in the teaching, teachers should start from the multi-dimensional perspective to inspire students to think about the problem, from a variety of aspects and angles to demonstrate the problem. Secondly, the appropriate use of archaeological data, we also need to pay attention to literature in the mythical literature. Analysis of the problem needs to start from a variety of elements, such as the discussion of vehicle rock arts, it is necessary to attach importance to the history of vehicles, but also pay attention to rock image associated with the relationship between space and cultural relations, attach importance to the elements analysis in the teaching as well, so that students can use the holistic view to analyze the problem. Thirdly, the use of image semantics decomposition method to decompose the relationship between the language and image, interpreting specific images and their relationship is essential, image semantic decomposition method is the interpretation of the image, especially has a revelation for the study of art theory, this kind of decomposition is coming from the semantic structure of the specific image case helps us to explain the cultural connotation of the image, from macroscopic to microscopic, and from the part to the whole body. It is especially useful for interpreting the specific image and the whole relationship between the images. Therefore, in the actual theoretical teaching, the above method can be applied to the actual teaching and research.

\section{Acknowledgements}

This is the results of the Humanities and Social Sciences Research Project of Xi'an Academy of Fine Arts in 2017 (Project No. 2017XK026)

\section{References}

[1] Zhai Defang. The starting research on the origin of carriage in Shang and Zhou Dynasties, Chinese Archeology, 1988, 1, 103-104.

[2] Wang Wei. Research on the origin of carriage", International Symposium on Chinese Shang Dynasty Culture, Beijing: China Encyclopedia Publishing House, 1998, 380-384.

[3] Wang Haicheng. The origin of Chinese carriage, Eurasian Journal, 3, Beijing: Zhonghua Book Company, 2002.

[4] Teganen Barry Seoul. The distribution characteristics and content analysis of vehicle rock arts in the eastern part of Eurasian grassland, Grassland Cultural Relics, 2, 49.

[5] Gai Shanlin. Yinshan rock arts, Beijing: Cultural Relics Press, 1986, 178.

[6] Wu Xiaoyun. Research on car buried in Shang and Zhou Dynasties, Beijing: Science Press, 2009, 12 and 207.

[7] Wang Xuerong. The emergence of rut and two-wheeled vehicles in early Shang Dynasty, three generations of civilized research editorial board: "Three generations of civilization" (a), Beijing: Science Press, 1999, 239-241.

[8] Sun Ji. Han dynasty culture materials map, Beijing: Cultural Relics Press, 1991, 90 and 110.

[9] Zhang Wenjing. The vehicle rock arts in Yinshan area of Inner Mongolia, Northern cultural relics", 2013, 1, 42. 
[10] Outram A.K, Stearna N.A, Bendrey R, et al. "The earliest horse harnessing and milking" [J]. Science, 2009, 323 (5919): 1332-1335.

[11] Ren Lele, Dong Guanghui. The origin and spread of the" six animals ", Nature Magazine, 2016, 4, 260.

[12] Xie Ruiju. Gansu Yongjing Qin Wei Jia Qi jia cultural cemetery, Archaeological Journal, 1975, 2,88 .

[13] Anati.E. Volcamonica, "Rock Art _-- A New History for Europe", Edizioni del Centro Camuno di Studi Preistorici. Brescia, 1994.

[14] A • Lommel, "Prehistory and Primitive Man", London, 1966, 47.

[15] Tang Huisheng, Zhang Wenhua. Qinghai rock paintings: prehistoric art binary opposition thinking and its concept research", Beijing: Science Press, 2001, 67-78.

[16] Gai Shanlin, Gai Zhihao. Interpretation of Inner Mongolia rock art culture, Beijing: Beijing Library Press, 2002, 440-441. 